\title{
Patients' expectations of returning to work, co-morbid disorders and work capacity at discharge from cardiac rehabilitation
}

This article was published in the following Dove Press journal: Vascular Health and Risk Management

\author{
Annett Salzwedel' \\ Rona Reibis ${ }^{2}$ \\ Miralem Hadzic ${ }^{\prime}$ \\ Hermann Buhlert ${ }^{3}$ \\ Heinz Völler ${ }^{1,3}$ \\ 'Department of Rehabilitation Research, \\ University of Potsdam, Potsdam, \\ Germany; ${ }^{2}$ Cardiological Outpatient \\ Clinik Am Park Sanssouci, Potsdam, \\ Germany; ${ }^{3}$ Department of Cardiology, \\ Klinik Am See, Rehabilitation Centre of \\ Cardiovascular Diseases, Rüdersdorf, \\ Germany
}

Objective: We aimed to characterize patients after an acute cardiac event regarding their negative expectations around returning to work and the impact on work capacity upon discharge from cardiac rehabilitation (CR).

Methods: We analyzed routine data of 884 patients ( $52 \pm 7$ years, $76 \%$ men) who attended 3 weeks of inpatient CR after an acute coronary syndrome (ACS) or cardiac surgery between October 2013 and March 2015. The primary outcome was their status determining their capacity to work (fit vs unfit) at discharge from CR. Further, sociodemographic data (eg, age, sex, and education level), diagnoses, functional data (eg, exercise stress test and 6-min walking test [6MWT]), the Hospital Anxiety and Depression Scale (HADS) and self-assessment of the occupational prognosis (negative expectations and/or unemployment, Würzburger screening) at admission to CR were considered.

Results: A negative occupational prognosis was detected in 384 patients (43\%). Out of these, 368 (96\%) expected not to return to work after CR and/or were unemployed before CR at $29 \%(\mathrm{n}=113)$. Affected patients showed a reduced exercise capacity (bicycle stress test: $100 \mathrm{~W}$ vs $118 \mathrm{~W}, P<0.01$; $6 \mathrm{MWT}$ : $380 \mathrm{~m}$ vs $421 \mathrm{~m}, P<0.01)$ and were more likely to receive a depression diagnosis $(12 \%$ vs $3 \%, P<0.01)$, as well as higher levels on the HADS. At discharge from CR, $21 \%$ of this group $(n=81)$ were fit for work (vs $35 \%$ of patients with a normal occupational prognosis $(\mathrm{n}=175, P<0.01)$ ). Sick leave before the cardiac event (OR $0.4,95 \%$ CI $0.2-0.6, P<0.01$ ), negative occupational expectations (OR $0.4,95 \%$ CI $0.3-0.7$, $P<0.01$ ) and depression (OR $0.3,95 \%$ CI $0.1-0.8, P=0.01$ ) reduced the likelihood of achieving work capacity upon discharge. In contrast, higher exercise capacity was positively associated.

Conclusion: Patients with a negative occupational prognosis often revealed a reduced physical performance and suffered from a high psychosocial burden. In addition, patients' occupational expectations were a predictor of work capacity at discharge from CR. Affected patients should be identified at admission to allow for targeted psychosocial care.

Keywords: cardiac rehabilitation, return to work, work capacity, negative expectation, occupational prognosis

\section{Introduction}

Besides medical care, cardiovascular risk factor management, exercise training and nutritional advice, according to the recommendations by the Cardiac Rehabilitation Section of the European Association of Preventive Cardiology (EAPC), comprehensive cardiac rehabilitation (CR) particularly includes psychosocial counseling and social support. ${ }^{1}$ Hereby, $\mathrm{CR}$ is based on the holistic approach of the
Correspondence: Annett Salzwedel Department of Rehabilitation Research, University of Potsdam, Am Neuen Palais

10, Potsdam 14469, Germany

Tel +49331977 406I

Email annett.salzwedel@uni-potsdam.de 
biopsychosocial model of the International Classification of Functioning, Disability and Health (ICF) by the World Health Organization. ${ }^{2}$ For patients of employable age, comprehensive CR provides a multidisciplinary, tailored strategy for the recovery of work capacity following an acute cardiac event, with the aim of vocational reintegration as a crucial step in coping with the disease.

Work capacity at discharge from $\mathrm{CR}$ can predict return to work (RTW). ${ }^{3}$ As an outcome of CR, work capacity is predominantly defined by physical capacity and fitness. In patients with coronary heart disease (CHD), fitness assessed by cardiopulmonary exercise testing (CPX) shows a significant prognostic value. ${ }^{4}$ Further, CPX is in turn a predictive tool for RTW as well as for retirement after CR. ${ }^{5}$ Ades et al confirmed fitness in CPX on entry to $\mathrm{CR}$ as very low, ${ }^{6}$ whereby the physical functioning in $\mathrm{CR}$ can be significantly enhanced. ${ }^{7}$ The authors stated the importance of $\mathrm{CR}$ in improving both physical function and prognosis.

Several additional medical and non-medical parameters that can rarely be influenced by $\mathrm{CR}$ affect vocational reintegration as well. ${ }^{8}$ Evident risk factors for non-RTW are the severity of acute coronary syndrome or left ventricular dysfunction, residual ischemia and existing comorbidities, as well as gender and educational level. ${ }^{9-11}$ Likewise, psychosocial and socio-occupational aspects, such as depression, low socioeconomic status, lack of social support, poor working conditions, an unfavorable socio-medical course before CR (eg, incapacity for work, unemployment and negative subjective expectations regarding RTW including the concern of not meeting work requirements) decrease the probability of successfully resuming occupation. ${ }^{12-16}$ Certainly, these environmental and personal factors are of comparable importance to medical ones. ${ }^{17,18}$

However, the causality and associations between the barriers to vocational reintegration mentioned above are largely unclear. In particular, the negative self-assessment of the occupational prognosis, which has been shown to reduce the probability of RTW six months after $\mathrm{CR}^{3,15}$ may be moderated by objective clinical limitations (eg, decreased physical function, fitness or comorbidities) and psychosocial disorders (eg, depressive symptoms).

For a better understanding of the underlying mechanisms, we aimed to characterize patients with negative expectations in terms of returning to work after an acute cardiac event and the impact on work capacity upon discharge from $\mathrm{CR}$.

\section{Methods}

\section{Study design and patients}

We conducted a single-center retrospective analysis of routine data from 967 consecutive patients up to 65 years of age who attended a CR program for an acute cardiac event or cardiac surgery between October 2013 and March 2015. Data from patients who were homemakers $(n=16)$ or prematurely retired $(\mathrm{n}=5)$, patients with early termination of CR (eg, transfer to hospital; $\mathrm{n}=30$ ) and patients without data for occupational prognosis or inconsistent data for current unemployment $(n=32)$ were excluded from the analysis. Accordingly, the resulting dataset included 884 cardiac patients.

\section{Cardiac rehabilitation program}

All patients participated in a comprehensive inpatient CR program predominantly following an acute cardiac event (eg, acute coronary syndrome [ACS], coronary artery bypass grafting $[\mathrm{CABG}]$, heart valve implantation) with a mean duration of three weeks, which usually starts within 14 days of being discharged from the hospital. ${ }^{19}$ Exercise training and sports therapy supervised by a cardiologist (eg, training on a bicycle ergometer, outdoor walking, resistance training, gymnastics), cardiovascular risk factor management, psychological support (eg, counseling/coping by a psychologist in single or group sessions), lifestyle adjustment and nutritional advice conducted by approved physical/sport therapists and psychotherapists are the main components of the program. ${ }^{19,20}$ The CR program is standardized according to the specifications of the German pension insurance and consists, on average, of 12 weekly training units and 8 additional counseling sessions. ${ }^{21}$

\section{Data source}

Sociodemographic data (eg, age, sex, educational level), cardiovascular diagnoses and comorbidities (eg, myocardial infarction $[\mathrm{MI}], \mathrm{CABG}$, heart valve implantation, peripheral artery disease [PAD], chronic obstructive pulmonary disease [COPD], diabetes mellitus [DM], depression diagnosis) and functional parameters (eg, left ventricular ejection fraction [LVEF], exercise bicycle stress test, 6-mins walking test [6MWT]), as well as values on the hospital anxiety and depression scale (HADS) were extracted from the clinic's electronic patient records. Diagnoses in the database were coded according to the International Statistical Classification of Diseases and Related Health Problems (ICD-10-Code). For the current 
analysis, we aggregated the single codes into groups or chapters depending on their frequency and relevance for the course of CR (Table 1).

Patients' occupational prognosis assessed via the Würzburger Screening test (WBS; clinical version) at admission to CR was evaluated. The WBS estimates the likelihood of returning to work (RTW) six months after CR, with acceptable sensitivity (86\%) and specificity $(82 \%) .^{15}$ This questionnaire includes a subscale for patients' expectations of RTW with 3 items (Do you think that you can return to your previous job after rehabilitation? Answer: yes/no; Are you currently thinking of applying for a pension (early retirement for health reasons)? Answer: yes/no; How soon after completing the rehabilitation do you hope to return to work? Within ... Answer: 1 month, more than 1 month, not at all). All items can generate 1 point for a negative answer and can be summed (score range $0-3$ points), where 1 point serves as a cut-off value for patients' negative expectations of RTW. In addition, the screening test includes an item for unemployment (question: Are you currently employed? Possible answers: (1) yes, full-time, (2) yes, part-time, (3) yes, parttime with less than 3 hrs per day, (4) yes, in occupational training, (5) homemaker, (6) no, unemployed, (7) no,

Table I Aggregation of cardiovascular diagnoses, comorbidities and procedures regarding ICD-I0-Code

\begin{tabular}{|l|l|}
\hline Diagnosis & ICD-10 Code \\
\hline Cardiovascular diagnosis and procedures & \\
\hline Myocardial infarction & 121 \\
Valvular heart disease & I34-I37 \\
Heart failure & I50 \\
Peripheral artery disease & I70-179 \\
CRT/implantable cardioverter defibrillator & Z95.0 \\
Coronary artery bypass graft & Z95.I \\
Heart valve implant & Z95.2-Z95.4 \\
Coronary stent & Z95.5 \\
Peripheral angioplasty & Z95.88 \\
\hline Comorbidities, cardiovascular risk factors & \\
\hline Diabetes mellitus & EI0-EI4 \\
COPD & J44 \\
Kidney disease & NI7-NI9 \\
Depression & F32-F33 \\
Sleep apnea & G47 \\
Spinal disease & M40-M54 \\
Smokers & FI7 \\
\hline
\end{tabular}

Abbreviations: CRT, cardiac resynchronization therapy; COPD, chronic obstructive pulmonary disease. temporary annuity and (8) no, permanently pensioned, with answers (6) and (7) detecting unemployment). In total, negative expectations of RTW and unemployment are defined as negative occupational prognoses. In the recruitment time frame, the WBS was consecutively conducted as screening for inclusion criteria in a randomized controlled trial that is described elsewhere. ${ }^{22}$

Additionally, the socio-medical assessment of patients including medical recommendations for further treatment and occupational reintegration (eg, further diagnostics, psychological support, lab/medication control, physiotherapy, CR Phase III, gradual resumption of work, functional training, occupational rehabilitation offers such as occupational retraining or education, assessment of employment limiting factors) by the $\mathrm{CR}$ cardiologist at $\mathrm{CR}$ discharge were taken from the electronic database. This assessment also includes work capacity as the primary outcome of this investigation. Work capacity was documented as a dichotomous variable with the categories of fit and unfit for work. Fit for work describes the condition when the patient is capable of performing his previous profession with a daily working capacity of more than 6 hrs (fulltime) or 3-6 hrs (part time). Both entities were summarized as "fit for work". This assessment is based on the clinical-cardiological, psychosocial and functional data at the end of the CR. Unfit for work means that the patient has a working capacity of less than $3 \mathrm{hrs}$ for the job that he/she has performed until the cardiac event.

\section{Ethics approval}

According to the responsible Institutional Review Board (IRB; Landesärztekammer Brandenburg - State Medical Association of Brandenburg), no informed consent by patients and no approval by the IRB was required, since this study retrospectively investigates anonymous singlecenter routine data. All patient data were treated confidentially in compliance with the Declaration of Helsinki.

\section{Statistics}

Continuous variables are expressed as means \pm standard deviation (SD), and categorical variables as absolute values and percentages. Group differences (normal vs negative occupational prognoses by WBS) were determined by independent samples $t$-test or $\mathrm{Chi}^{2}$ test. Work capacity (fit vs unfit) at discharge from $\mathrm{CR}$ as assessed by $\mathrm{CR}$ cardiologist was analyzed using a logistic regression model with stepwise backward selection to identify independent associations. Age, sex, the subjective occupational prognosis 
(categories: (1) patients' negative expectations of RTW, (2) patients' negative expectations of RTW and unemployment, (3) unemployment), sick leave before the cardiac event, cardiovascular diagnoses (eg, MI, valvular heart disease, PAD, cardiomyopathy, arrhythmia), comorbidities and cardiovascular risk factors (eg, DM, COPD, kidney disease, depression, spinal disease, smoking, obesity), procedures (eg, pacemaker/cardioverter defibrillator implantation, CABG, valve implantation, peripheral angioplasty) and functional and performance parameters (eg, heart rate, LVEF, 6MWT, max. exercise capacity, HADS) were taken into account in the modeling. The effect-size estimates (relative odds ratios [OR]) of the predicting variables are shown with $95 \%$ confidence intervals and $p$-values, with $5 \%$ as the level of statistical significance. Calculations were conducted using SPSS 24 (IBM, Chicago, IL, USA).

\section{Results \\ Population}

About half of the patients (mean age: $52.7 \pm 6.7$ years, $76 \%$ men) were admitted to CR after an acute MI (51\%). 53\% underwent a coronary stenting and $17 \%$ an elective or subsequent CABG. A valvular disease was documented in $13 \%$ of patients. The majority of patients $(83 \%)$ were on sick leave before their cardiac event (Table 2).

Among the comorbidities and cardiovascular risk factors, nicotine abuse was the most common diagnosis at $39 \%$, followed by DM at $18 \%$. $9 \%$ of patients suffered from back pain symptoms, and $7 \%$ had a depression diagnosis (Table 2).

\section{Patient characteristics according to self- assessed occupational prognosis}

Out of the investigated population, 384 patients (43\%) were positively screened for a negative occupational prognosis by WBS. In this group, 368 patients $(96 \%)$ had negative expectations of RTW after CR; 113 (29\%) were unemployed before CR (Figure 1).

Patients with a negative occupational prognosis were more likely to be women ( $28 \%$ vs $20 \%, P=0.01$ ), were more often on sick leave before the index event $(86 \%$ vs $82 \%, P<0.01$ ), and received a CABG in a higher proportion $(24 \%$ vs $12 \%, P<0.01)$ than those with negative screening results. Further, affected patients suffered more frequently from a diagnosis of depression $(12 \%$ vs $3 \%$, $P<0.01)$ and showed higher depression and anxiety values on the HADS overall. In addition, patients with a negative occupational prognosis revealed a reduced exercise capacity (Table 2).

\section{Work capacity at rehabilitation discharge}

At discharge from $\mathrm{CR}, 21 \%$ of patients with a negative occupational prognosis by WBS $(\mathrm{n}=81)$ were fit for work. In contrast, $35 \%$ of patients with a normal occupational prognosis were classified as fit for work by $\mathrm{CR}$ cardiologists upon discharge from CR $(\mathrm{n}=175, P<0.01)$.

The probability of achieving a positively assessed work capacity at discharge was reduced by sick leave before the cardiac event (OR 0.4, 95\% CI 0.2-0.6, P<0.01) and patients' negative expectations of RTW (OR 0.4, 95\% CI $0.3-0.7, P<0.01)$. Further, a depression diagnosis was negatively associated with work capacity (OR $0.3,95 \%$ CI $0.1-0.8, P=0.01)$. Similarly, a cardiac surgery as well as several comorbidities (PAD, COPD, DM) limited work capacity at discharge. Unemployment in addition to negative expectations of RTW and higher physical performance (eg, LVEF, 6MWT, exercise capacity) were positively associated (Figure 2).

Regarding the recommendations for further treatment by clinicians at $\mathrm{CR}$ discharge, there were statistically significant differences for patients with normal and negative occupational prognoses, respectively, in psychological support (11\% vs $2 \%, P<0.01)$, further diagnostics $(29 \%$ vs $22 \%, P=0.03$ ), lab/medication control ( $34 \%$ vs $28 \%$, $P=0.04)$ and occupational rehabilitation offers $(10 \%$ vs $2 \%, P<0.01)$. In addition, group differences were found in the assessed factors that could potentially limit employment (mental/psychological resilience: $7 \%$ vs $2 \%, P<0.01$, musculoskeletal restrictions: $39 \%$ vs $22 \%, P<0.01$ ).

\section{Discussion}

In the present study, a remarkably high proportion of patients with negative occupational prognoses and, in particular, negative expectations regarding their return to work after CR were assessed. Streibelt \& Brünger showed a $32 \%$ prevalence rate for a negative occupational prognosis in a CR population, with $16 \%$ of patients not expecting to return to work. ${ }^{23}$ In this investigation, patients in subsequent $\mathrm{CR}$ after acute coronary syndrome and cardiac revascularization or coronary bypass surgery were excluded. In another German single-center study, approximately $30 \%$ of younger patients $(<50$ years $)$ stated that they probably or certainly expected problems with resuming their occupation following an acute cardiac event, whereas patients recovering from $\mathrm{CABG}$ or with severe 
Table 2 Baseline characteristics $(\mathrm{N}=884)$

\begin{tabular}{|c|c|c|c|c|}
\hline \multirow[t]{3}{*}{ Parameter } & \multirow{2}{*}{$\begin{array}{l}\text { Total } \\
(n=884)\end{array}$} & \multicolumn{2}{|c|}{ Occupational prognosis } & \multirow[t]{3}{*}{$P$-value } \\
\hline & & Normal $(n=500)$ & Negative $(n=384)$ & \\
\hline & $M \pm S D / N(\%)$ & M $\pm S D / N(\%)$ & MISD/N (\%) & \\
\hline \multicolumn{5}{|l|}{ Sociodemographic data } \\
\hline Age (years) & $51.7 \pm 6.7$ & $51.9 \pm 6.4$ & $51.5 \pm 7.0$ & 0.397 \\
\hline Sex (male) & $676(75.8)$ & $398(79.6)$ & $278(72.4)$ & 0.012 \\
\hline Living alone & $210(23.8)$ & $106(21.3)$ & $104(27.2)$ & 0.044 \\
\hline Sick leave before cardiac event & $737(83.4)$ & $408(81.6)$ & $329(85.7)$ & 0.006 \\
\hline \multicolumn{5}{|l|}{ Cardiovascular diagnoses } \\
\hline Acute myocardial infarction & $454(5 \mid .4)$ & $275(55.0)$ & $179(46.6)$ & 0.013 \\
\hline Valvular disease & $117(13.2)$ & $67(13.4)$ & $50(\mid 3.0)$ & 0.869 \\
\hline Heart failure & $46(5.2)$ & $27(5.4)$ & $19(4.9)$ & 0.764 \\
\hline PAD & $148(16.7)$ & $73(14.6)$ & $75(19.5)$ & 0.052 \\
\hline \multicolumn{5}{|l|}{ Procedures } \\
\hline CRT/implantable cardioverter defibrillator & $43(4.9)$ & $16(3.2)$ & $27(7.0)$ & 0.009 \\
\hline CABG & $153(17.3)$ & $60(12.0)$ & $93(24.2)$ & $<0.001$ \\
\hline Heart valve implantation & $101(11.4)$ & $51(10.2)$ & $50(13.0)$ & 0.191 \\
\hline Coronary stenting & 47I (53.3) & $298(59.6)$ & $173(45.1)$ & $<0.001$ \\
\hline Peripheral angioplasty & $28(3.2)$ & II (2.2) & $17(4.4)$ & 0.061 \\
\hline \multicolumn{5}{|l|}{ Comorbidities/risk factors } \\
\hline Diabetes mellitus & $157(17.8)$ & $81(16.2)$ & $76(19.8)$ & 0.166 \\
\hline COPD & $48(5.4)$ & $21(4.2)$ & $27(7.0)$ & 0.066 \\
\hline Kidney disease & $28(3.2)$ & II (2.2) & $17(4.4)$ & 0.061 \\
\hline Depression (diagnosed) & $60(6.8)$ & $16(3.2)$ & $44(11.5)$ & $<0.001$ \\
\hline Sleep apnea & $36(4.1)$ & $14(2.8)$ & $22(5.7)$ & 0.029 \\
\hline Spinal disease & $82(9.3)$ & $36(7.2)$ & $46(12.0)$ & 0.015 \\
\hline Smokers & $345(39.0)$ & $216(43.2)$ & $129(33.6)$ & 0.004 \\
\hline \multicolumn{5}{|l|}{ Functional parameters } \\
\hline LVEF (\%) & $55.0 \pm 8.9$ & $56.0 \pm 8.5$ & $53.8 \pm 9.2$ & $<0.001$ \\
\hline Max. exercise capacity (Watt) & $110.2 \pm 35.0$ & $117.7 \pm 33.2$ & $99.8 \pm 34.8$ & $<0.001$ \\
\hline 6-min walk distance (meter) & $403.2 \pm 74.8$ & $420.8 \pm 61.8$ & $380.1 \pm 83.7$ & $<0.001$ \\
\hline HADS-depression (point) & $5.7 \pm 4.1$ & $4.9 \pm 3.8$ & $6.9 \pm 4.3$ & $<0.001$ \\
\hline HADS-anxiety (point) & $6.7 \pm 4.3$ & $5.9 \pm 4.0$ & $7.7 \pm 4.4$ & $<0.001$ \\
\hline
\end{tabular}

Abbreviations: CABG, coronary artery bypass graft; CRT, cardiac resynchronization therapy; COPD, chronic obstructive pulmonary disease; LVEF, left ventricular ejection fraction; HADS, hospital anxiety and depression scale; PAD, peripheral artery disease.

comorbid disorders were not considered. ${ }^{24} \mathrm{~A}$ more comparable patient population was investigated in our own recent population, describing that only $17.5 \%$ of cases did not expect to return to work. ${ }^{3}$ However, the heterogeneous prevalence rates may result from the use of different screening tools or criteria for self-assessed occupational prognoses.

In general, patients with a negative occupational prognosis in the present analysis showed poorer health conditions at discharge as evidenced by comorbidities such as diabetes mellitus or musculoskeletal disorders after having had surgery or sick leave prior to the cardiac index event, as well as significantly lower physical and exercise capacity. In addition, psychological issues such as depression diagnoses as well as positive screening results were striking in this patient group. These findings were also reflected in the recommendations of cardiologists at $\mathrm{CR}$ discharge. Ultimately, negative expectations of RTW as well as depression and physical capacity were strongly associated with patients' work capacity at discharge from CR.

The impact of the above-mentioned parameters such as comorbidities on vocational reintegration is well known. ${ }^{10,11}$ In particular, depression is an evident determinant of $\mathrm{RTW}^{3,17,25}$ and later detachment from employment. ${ }^{26}$ 


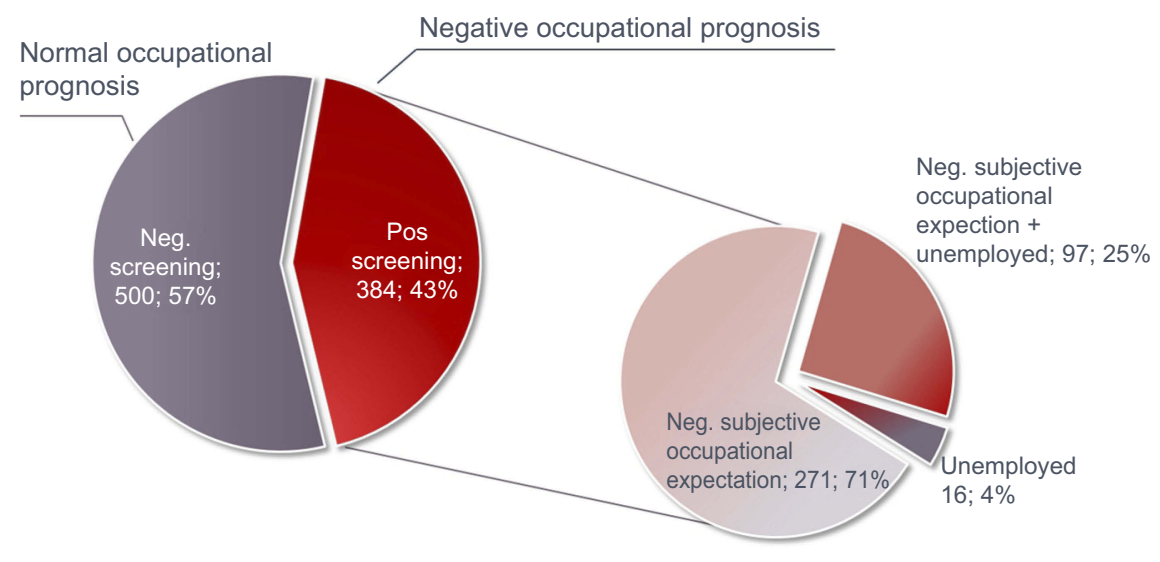

Figure I Proportion of patients with negative occupational prognosis according to Würzburger Screening in CR.

Abbreviations: CR, cardiac rehabilitation; Neg., negative; Pos., positive.

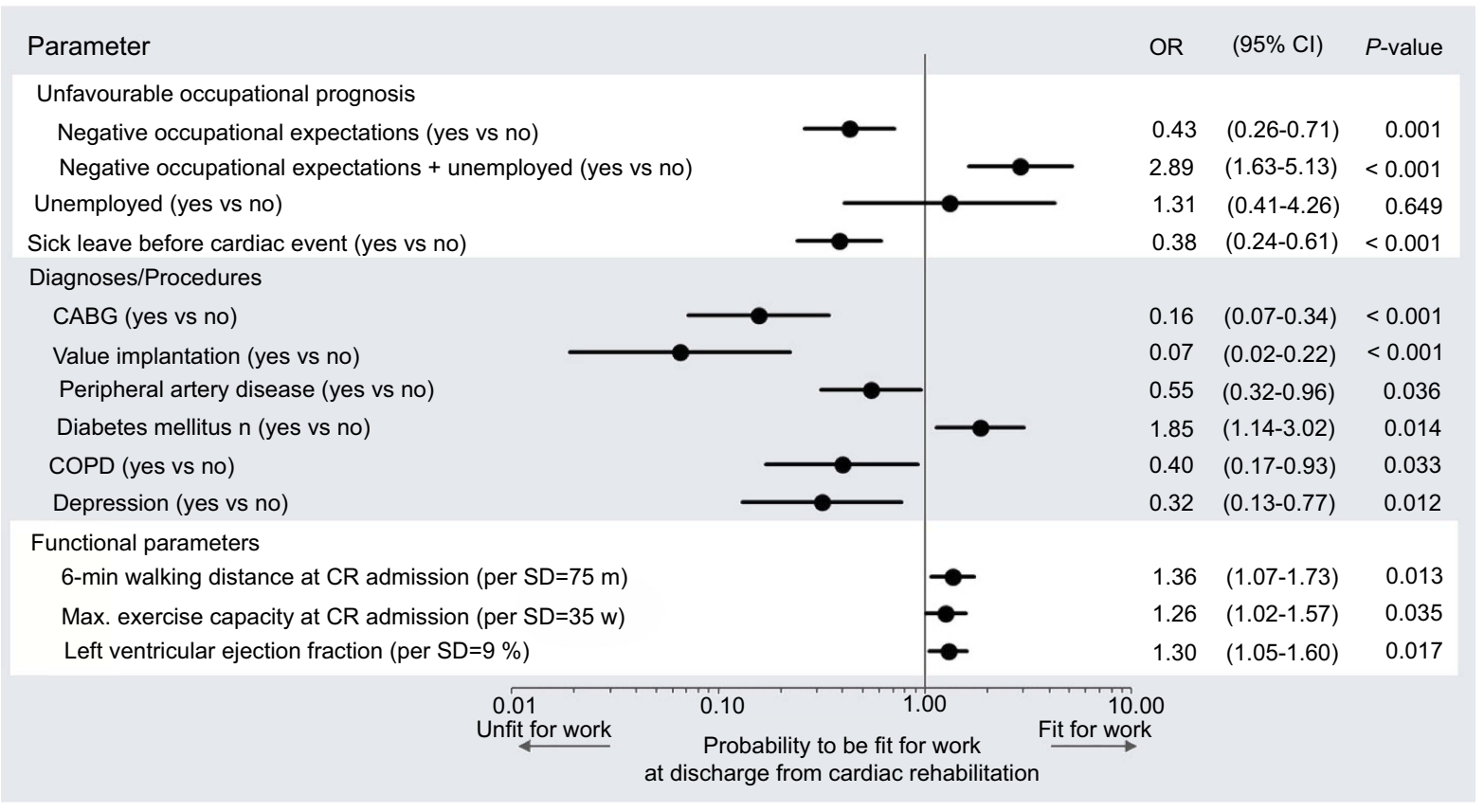

Figure 2 Predictors of work capacity at discharge from CR.

Notes: Forest plot shows the results of logistic regression modeling. Negative patient expectations of returning to work assessed by Würzburger Screening ${ }^{15}$ reduced the probability of being fit for work at discharge by $57 \%$, sick leave before cardiac event by $62 \%$ and depression diagnosis by $68 \%$, whereas a higher physical performance was positively associated with work capacity (total cases in the model $\mathrm{n}=772$, employable $\mathrm{n}=249 ; 29 \%$; Nagelkerke's $R^{2} 0.324$ ).

Abbreviations: CABG, coronary artery bypass graft; $\mathrm{Cl}$, confidence interval; COPD, chronic obstructive pulmonary disease; CR, cardiac rehabilitation; OR, odds ratio; SD, standard deviation.

Similarly, depression impairs exercise capacity both before and after three weeks of comprehensive rehabilitation, as Kazukauskiene et al explored in 223 patients with $\mathrm{CHD}^{27}$ Thus, depression is of clinical prognostic significance. ${ }^{28,29}$ Apart from that, self-assessed occupational prognosis, physical capacity and work capacity are independent predictors of RTW in patients with cardiovascular diseases. ${ }^{3,5,17}$

Besides the significance of the single parameters, the reported data indicate a complex interdependent relationship.
Statements about causality cannot be made. Even if there were no relevant interactions in statistical modeling due to insufficient power, a moderating or mediating linkage between psychosocial disorders and negatively self-assessed occupational prognosis is conceivable. Moreover, negative illness perception and resulting anxiety might force depression and non-expected RTW in this population. ${ }^{30}$ Also, from the patients' point of view, RTW after an ACS seems to be a multi-factorial issue. Slebus et al demonstrated by means of a 
semi-structured telephone survey that patients see a multitude of hindering factors in terms of RTW. ${ }^{31}$ In this regard, the focus was on physical incapacity, comorbidities and mental incapacity.

Overall, the recent findings point to the need to consider contextual factors according to the biopsychosocial model following the $\mathrm{ICF}^{2}$ in $\mathrm{CR}$. The assessment of patients' expectations regarding return to work upon admission to $\mathrm{CR}$ seems to be a simple instrument for identifying vulnerable patients with a likely need for support by social workers and/or psychologists. The latter can be identified using a gradual psychodiagnostic program ${ }^{32}$ starting with a short standardized depression screening tool such as a short-version patient health questionnaire (PHQ), ${ }^{33}$ which is time-saving and can be easily conducted during the $\mathrm{CR}$ admission interview. A recent published review of the Working Group on Secondary Prevention and Rehabilitation of the EAPC provides strategies and an algorithm for the interaction of CR professionals for the evaluation of work capacity and reintegration of patients after an acute coronary syndrome. ${ }^{8}$ Nonetheless, there is a need for long-term support concerning RTW after CR to help patients begin employment, as recent data also prove. $^{26}$

\section{Limitations}

This analysis is limited due to the uni-centric retrospective design. In particular, there was no possibility to follow up with patients and their occupational status after discharge from CR. Second, patients' data were from the clinical routine. Therefore, we cannot exclude coding and documentation errors. Furthermore, there are missing data on several mainly functional parameters. This reduced the power of the multivariable statistical analysis. Statistical modeling under consideration of parameter changes during $\mathrm{CR}$ and additional potential confounders was not feasible.

The proportion of female patients in the investigated population was low. It corresponds to previous studies and comparable investigations. Although the benefits of an effective CR are comparable for both genders, women are less likely to be enrolled in CR programs, especially after cardiac surgery. Underutilization of $\mathrm{CR}$ is mainly based on psychosocial and infrastructural barriers. Until now, the majority of information available about the cardiovascular benefits has been derived from studies predominantly investigating men, despite the fact that the rehabilitation process seems to play an ascertainable role in improving quality of life, exercise tolerance and optimization of risk factors in women as well, if specific needs of women during CR are considered.

\section{Conclusion}

A high proportion of patients in $\mathrm{CR}$ after a cardiac event expected not to return to work. As these patients often showed reduced physical performance and suffered from a high adverse psychosocial burden, negative self-assessment of the occupational prognosis seems to indicate a vulnerable patient population. In addition, patients' expectation of returning to work is a predictor of employable discharge from CR. Therefore, affected patients should be identified already at admission to $\mathrm{CR}$ in order to facilitate a targeted psychosocial intervention.

\section{Acknowledgments}

Preliminary data were presented at the 12th World Congress of the International Society of Physical and Rehabilitation Medicine (ISPRM 2018), Paris, France, 2018, and at the Annual European Society of Cardiology congress in Munich, Germany, 2018.

\section{Disclosure}

The authors report no conflicts of interest in this work.

\section{References}

1. Piepoli MF, Corrà U, Benzer W, et al. Secondary prevention through cardiac rehabilitation: from knowledge to implementation. A position paper from the Cardiac Rehabilitation Section of the European Association of Cardiovascular Prevention and Rehabilitation. Eur J Cardiovasc Prev Rehabil. 2010;17(1):1-17. doi:10.1097/HJR.0b013e3283313592

2. World Health Organization.International Classification of Functioning, Disability and Health: ICF. Geneva: WHO; 2001.

3. Salzwedel A, Reibis R, Heidler M-D, Wegscheider K, Völler H. Determinants of return to work after multi-component cardiac rehabilitation. Archiv Phys Med Rehabil. 2019. doi:10.1016/j.apmr.2019.04.003

4. Keteyian SJ, Brawner CA, Savage PD, et al. Peak aerobic capacity predicts prognosis in patients with coronary heart disease. Am Heart $J$. 2008;156(2):292-300. doi:10.1016/j.ahj.2008.03.017

5. Salzwedel A, Reibis R, Wegscheider K, et al. Cardiopulmonary exercise testing is predictive of return to work in cardiac patients after multicomponent rehabilitation. Clin Res Cardiol. 2016;105(3):257267. doi:10.1007/s00392-015-0917-1

6. Ades PA, Savage PD, Brawner CA, et al. Aerobic capacity in patients entering cardiac rehabilitation. Circulation. 2006;113(23):2706-2712. doi:10.1161/CIRCULATIONAHA.105.606624

7. Ades PA, Maloney A, Savage P, Carhart RL. Determinants of physical functioning in coronary patients: response to cardiac rehabilitation. Arch Intern Med. 1999;159(19):2357-2360.

8. Reibis R, Salzwedel A, Abreu A, et al. The importance of return to work: how to achieve optimal reintegration in ACS patients. Eur J Prev Cardiol. 2019:2047487319839263. doi:10.1177/2047487319839263

9. Bhattacharyya MR, Perkins-Porras L, Whitehead DL, Steptoe A. Psychological and clinical predictors of return to work after acute coronary syndrome. Eur Heart J. 2007;28(2):160-165. doi:10.1093/ eurheartj/ehl440 
10. Osler M, Mårtensson S, Prescott E, Carlsen K. Impact of gender, comorbidity and social factors on labour market affiliation after first admission for acute coronary syndrome. A cohort study of Danish patients 2001-2009. PLOS ONE. 2014;9(1):e86758. doi:10.1371/journal.pone.0086758

11. Worcester MU, Elliott PC, Turner A, et al. Resumption of work after acute coronary syndrome or coronary artery bypass graft surgery. Heart Lung Circ. 2014;23(5):444-453. doi:10.1016/j.hlc.2013.10.093

12. Dreyer RP, Xu X, Zhang W, et al. Return to work after acute myocardial infarction: comparison between young women and men. Circ Cardiovasc Qual Outcomes. 2016;9(2 Suppl 1):S45-S52. doi:10.1161/CIRCOUTCOMES.115.002611

13. Jonge P, Zuidersma M, Bültmann U. The presence of a depressive episode predicts lower return to work rate after myocardial infarction. Gen Hosp Psychiatry. 2014;36(4):363-367. doi:10.1016/j. genhosppsych.2014.03.006

14. Biering K, Nielsen TT, Rasmussen K, Niemann T, Hjollund NH. Return to work after percutaneous coronary intervention: the predictive value of self-reported health compared to clinical measures. PLoS ONE. 2012;7(11):e49268. doi:10.1371/journal.pone.0049268

15. Löffler S, Wolf HD, Vogel H. Das Würzburger Screening zur Identifikation von beruflichen Problemlagen - entwicklung und Validierung. Gesundheitswesen. 2008;70(07). doi:10.1055/s-00281086302

16. Engblom E, Korpilahti K, Hämäläinen H, Rönnemaa T, Puukka P. Quality of life and return to work 5 years after coronary artery bypass surgery. Long-term results of cardiac rehabilitation. J Cardiopulm Rehabil. 1997;17(1):29-36.

17. Gragnano A, Negrini A, Miglioretti M, Corbière M. Common psychosocial factors predicting return to work after common mental disorders, cardiovascular diseases, and cancers: a review of reviews supporting a cross-disease approach. J Occup Rehabil. 2017. doi:10.1007/s10926-017-9714-1

18. Stendardo M, Bonci M, Casillo V, et al. Predicting return to work after acute myocardial infarction: socio-occupational factors overcome clinical conditions. PLoS ONE. 2018;13(12):e0208842. doi:10.1371/journal.pone.0208842

19. Karoff M, Held K, Bjarnason-Wehrens B. Cardiac rehabilitation in Germany. Eur J Cardiovasc Prev Rehabil. 2007;14(1):18-27. doi:10.1097/HJR.0b013e3280128bde

20. Rauch B, Riemer T, Schwaab B, et al. Short-term comprehensive cardiac rehabilitation after AMI is associated with reduced 1-year mortality: results from the OMEGA study. Eur J Prev Cardiol. 2014;21(9):1060-1069. doi:10.1177/2047487313486040

21. Benzer W, Rauch B, Schmid J-P, et al. Exercise-based cardiac rehabilitation in twelve European countries results of the European cardiac rehabilitation registry. Int $J$ Cardiol. 2017;228:58-67. doi:10.1016/j.ijcard.2016.11.059
22. Salzwedel A, Wegscheider K, Schulz-Behrendt C, Dörr G, Reibis R, Völler H. No impact of an extensive social intervention program on return to work and quality of life after acute cardiac event: a cluster randomized trial in patients with negative occupational prognosis. Int Archiv Occup Environ Health. 2019. (in press). doi:10.1007/s00420019-01450-3

23. Streibelt M, Brünger $M$. Wie viele arbeitsbezogene Leistungen bekommen Patienten mit besonderen beruflichen Problemlagen? Analyse einer repräsentativen indikationsübergreifenden Stichprobe von Rehabilitanden. Rehabilitation (Stuttg). 2014;53(6):369-375. doi:10.1055/s-0034-1375643

24. Budde HG, Keck M. Prädiktoren der beruflichen Wiedereingliederung nach stationärer kardiologischer Rehabilitation im Rahmen der Arbeiterrentenversicherung. Rehabilitation (Stuttg). 2001;40(4):208216. doi:10.1055/s-2001-15988

25. O’Neil A, Sanderson K, Oldenburg B. Depression as a predictor of work resumption following myocardial infarction (MI): a review of recent research evidence. Health Qual Life Outcomes. 2010;8:95. doi:10.1186/1477-7525-8-95

26. Smedegaard L, Numé A-K, Charlot M, Kragholm K, Gislason G, Hansen PR. Return to work and risk of subsequent detachment from employment after myocardial infarction: insights from danish nationwide registries. J Am Heart Assoc. 2017;6(10). doi:10.1161/ JAHA.117.006486

27. Kazukauskiene N, Burkauskas J, Macijauskiene J, et al. Mental distress factors and exercise capacity in patients with coronary artery disease attending cardiac rehabilitation program. Int J Behav Med. 2018;25(1):38-48. doi:10.1007/s12529-017-9675-y

28. Sundbøll J. Depression, stroke, and dementia in patients with myocardial infarction. Dan Med J. 2018;65(4):pii:B5423.

29. Carney RM, Freedland KE. Depression and coronary heart disease. Nat Rev Cardiol. 2017;14(3):145-155. doi:10.1038/nrcardio.2016.181

30. Broadbent E, Ellis CJ, Thomas J, Gamble G, Petrie KJ. Further development of an illness perception intervention for myocardial infarction patients: a randomized controlled trial. Journal of Psychosomatic Research. 2009;67(1):17-23. doi:10.1016/j.jpsychores.2008.12.001

31. Slebus FG, Jorstad HT, Peters RJ, et al. Return to work after an acute coronary syndrome: patients' perspective. Saf Health Work. 2012;3 (2):117-122. doi:10.5491/SHAW.2012.3.2.117

32. Vogel B, Jahed J, Bengel J, Barth J, Härter M, Baumeister H. Implementierung eines psychodiagnostischen Stufenplans in der medizinischen Rehabilitation - Ergebnisse einer Pilotstudie. Rehabilitation (Stuttg). 2009;48(6):361-368. doi:10.1055/s-0029-1241810

33. Elderon L, Smolderen KG, Na B, Whooley MA. Accuracy and prognostic value of American Heart Association: recommended depression screening in patients with coronary heart disease: data from the Heart and Soul Study. Circ Cardiovasc Qual Outcomes. 2011;4(5):533-540. doi:10.1161/CIRCOUTCOMES.110.960302
Vascular Health and Risk Management

\section{Publish your work in this journal}

Vascular Health and Risk Management is an international, peerreviewed journal of therapeutics and risk management, focusing on concise rapid reporting of clinical studies on the processes involved in the maintenance of vascular health; the monitoring, prevention and treatment of vascular disease and its sequelae; and the involvement of metabolic disorders, particularly diabetes. This journal is indexed on PubMed Central and MedLine. The manuscript management system is completely online and includes a very quick and fair peerreview system, which is all easy to use. Visit http://www.dovepress. com/testimonials.php to read real quotes from published authors. 